\title{
TSC-associated neuropsychiatric disorders (TAND): findings from the TOSCA natural history study
}

Petrus J. de Vries ${ }^{1 *}$, Elena Belousova ${ }^{2}$, Mirjana P. Benedik ${ }^{3}$, Tom Carter ${ }^{4}$, Vincent Cottin ${ }^{5}$, Paolo Curatolo ${ }^{6}$, Maria Dahlin ${ }^{7}$, Lisa D'Amato ${ }^{8}$, Guillaume B. d'Augères ${ }^{9}$, José C. Ferreira ${ }^{10}$, Martha Feucht ${ }^{11}$, Carla Fladrowski ${ }^{12,13}$, Christoph Hertzberg ${ }^{14}$, Sergiusz Jozwiak ${ }^{15}$, J. Chris Kingswood ${ }^{16}$, John A. Lawson ${ }^{17}$, Alfons Macaya ${ }^{18}$, Ruben Marques ${ }^{8,19}$, Rima Nabbout ${ }^{20}$, Finbar O'Callaghan ${ }^{21}$, Jiong Qin ${ }^{22}$, Valentin Sander ${ }^{23}$, Matthias Sauter ${ }^{24}$, Seema Shah ${ }^{25}$, Yukitoshi Takahashi ${ }^{26}$, Renaud Touraine ${ }^{27}$, Sotiris Youroukos ${ }^{28}$, Bernard Zonnenberg ${ }^{29}$, Anna C. Jansen ${ }^{30}$ on behalf of TOSCA Consortium and TOSCA Investigators

\begin{abstract}
Background: Most evidence for TSC-associated neuropsychiatric disorders (TAND) to date have come from small studies and case reports, and very little is known about TAND in adults. We explored baseline TAND data from the large-scale international TOSCA natural history study to compare childhood and adult patterns, describe age-based patterns, and explore genotype-TAND correlations.

Results: The study enrolled 2216 eligible participants with TSC from 170 sites across 31 countries at the data cut-off for the third interim analysis (data cut-off date: September 30, 2015). The most common behavioural problems (reported in $>10 \%$ of participants) were overactivity, sleep difficulties, impulsivity, anxiety, mood swings, severe aggression, depressed mood, self-injury, and obsessions. Psychiatric disorders included autism spectrum disorder (ASD, 21.1\%), attention deficit hyperactivity disorder (ADHD, 19.1\%), anxiety disorder (9.7\%), and depressive disorder (6.1\%). Intelligence quotient (IQ) scores were available for 885 participants. Of these, 44.4\% had normal IQ, while mild, moderate, severe, and profound degrees of intellectual disability (ID) were observed in 28.1, 15.1, 9.3, and 3. $1 \%$, respectively. Academic difficulties were identified in $58.6 \%$ of participants, and neuropsychological deficits (performance $<5$ th percentile) in $55.7 \%$. Significantly higher rates of overactivity and impulsivity were observed in children and higher rates of anxiety, depressed mood, mood swings, obsessions, psychosis and hallucinations were observed in adults. Genotype-TAND correlations showed a higher frequency of self-injury, ASD, academic difficulties and neuropsychological deficits in TSC2. Those with no mutations identified (NMI) showed a mixed pattern of TAND manifestations. Children and those with TSC2 had significantly higher rates of intellectual disability, suggesting that age and genotype comparisons should be interpreted with caution.
\end{abstract}

Conclusions: These results emphasize the magnitude of TAND in TSC and the importance of evaluating for neuropsychiatric comorbidity in all children and adults with TSC, across TSC1 and TSC2 genotypes, as well as in those with no mutations identified. However, the high rates of unreported or missing TAND data in this study underline the fact that, even in expert centres, TAND remains underdiagnosed and potentially undertreated.

Keywords: TSC-associated neuropsychiatric disorders, Tuberous sclerosis complex, TOSCA

\footnotetext{
* Correspondence: petrus.devries@uct.ac.za

'Division of Child and Adolescent Psychiatry, University of Cape Town, 46

Sawkins Road, Rondebosch, Cape Town 7700, South Africa

Full list of author information is available at the end of the article
}

(c) The Author(s). 2018 Open Access This article is distributed under the terms of the Creative Commons Attribution 4.0 International License (http://creativecommons.org/licenses/by/4.0/), which permits unrestricted use, distribution, and reproduction in any medium, provided you give appropriate credit to the original author(s) and the source, provide a link to the Creative Commons license, and indicate if changes were made. The Creative Commons Public Domain Dedication waiver (http://creativecommons.org/publicdomain/zero/1.0/) applies to the data made available in this article, unless otherwise stated. 


\section{Background}

Tuberous sclerosis complex (TSC) is an autosomal dominant genetic disorder characterized by the formation of hamartomas in multiple organ systems with a wide diversity of symptoms and severity across individuals [1, 2]. The majority of individuals with TSC have central nervous system involvement with a wide range of structural manifestations, such as cortical tubers, subependymal nodules, and aberrations of gray and white matter as well as high rates of functional manifestations, such as epilepsy, intellectual disability (ID), and behavioural problems [3-5]. The neurological, neuropsychiatric, and renal manifestations represent the greatest burden of disease of all TSC-related manifestations [3].

TSC-associated neuropsychiatric disorders (TAND) is an umbrella term coined by the Neuropsychiatry Panel of the 2012 International Consensus Conference for TSC, and encompasses a range of neuropsychiatric manifestations across various levels of investigation [2, 3, 5]. These include the behavioural level (observed behaviours such as sleep problems or aggressive behaviours), the psychiatric level (DSM/ICD defined psychiatric disorders such as autism spectrum disorders [ASD] or attention deficit hyperactivity disorder [ADHD]), the intellectual level (intellectual ability as defined by intelligence quotient [IQ]-type tests), the academic level (learning disorders, e.g., reading or mathematics difficulties), and the psychosocial level (e.g., self-esteem, family difficulties) $[3,5,6]$. TAND represent a significant burden of disease and have a major impact on quality of life of individuals with TSC and their families, given their impact on education, employment, and social life of patients and their family $[3,5]$.

The rate and pattern of TAND vary greatly among patients with TSC [3, 5, 7-11]. Overall, about $90 \%$ of individuals with TSC exhibit TAND features to some extent during their lifetime, with ASD and ID reported in up to $50 \%$ of individuals $[3,5,6]$. Results show differential rates in those with and without ID [12]. However, even individuals with normal intellectual abilities are at risk of developing TAND manifestations, particularly in the academic, neuropsychological, and psychosocial domains [8]. Despite the high rates of TAND, a 2010 survey of members of the Tuberous Sclerosis Association in the United Kingdom indicated that only $20 \%$ of individuals with TSC had ever received any assessment or treatment for TAND, suggesting a large assessment and treatment gap $[5,6,12,13]$. It is important to acknowledge that the majority of evidence for rates and patterns of TAND to date have come from relatively small studies and case reports. The largest published studies to date have included a few hundred participants [10, 12, 14]. Furthermore, very little TAND data are available about adults with TSC [15] or about the age-based pattern of TAND.
The underlying aetiology of TAND is likely to be combinatorial and multifactorial [16]. There is evidence that the genetic aberrations of TSC may be sufficient to cause TAND manifestations, $[16,17]$ with combinatorial and interactive contribution from functional and structural factors [16-22]. Individuals with TSC2 mutations have been reported to have a greater likelihood of ID than those with TSC1, [23-26] but both TSC1 and TSC2 mutations have been associated with the full range of intellectual ability from high IQ to profound ID $[25,26]$. Individuals with no mutation identified (NMI) after genetic testing have typically been described to have ID profiles between those with TSC1 and TSC2 [23-26]. These studies have also been based on relatively small samples and no study to date has examined other aspects of TAND in relation to genotype.

The largest natural history study of TSC to date - the TOSCA (TuberOus SClerosis registry to increase disease Awareness) study is a multi-centre, international disease registry designed with the aim of providing deeper insights into the manifestations of TSC and its management [27, 28]. In a previous publication outlining baseline findings from the TOSCA cohort of 2093 individuals, we presented topline findings of TAND features in the largest TSC cohort reported globally to date [28]. Results showed that ID was observed in 54\% of the evaluated participants and suggested that psychiatric disorders were typically diagnosed late. We also identified significant non-reported or missing data, which suggested that even in expert TSC centres around the globe, TAND may be underdiagnosed and therefore under-treated [28].

Here, we performed a detailed exploration of the largest TAND dataset to date using TOSCA baseline data of all the patients enrolled at the cut-off of September 30, 2015, with the specific aim of comparing childhood and adult TAND profiles, describing the age-related pattern of TAND, and examining TAND in relation to genotype.

\section{Methods}

A detailed description of the methods of the TOSCA registry has been provided previously [27]. In short, individuals of any age with a documented visit for TSC before 12 months of enrollment or newly diagnosed with TSC were included in the study between August 2012 and August 2014.

Information on participant demography, family history, genotype, vital signs, prenatal history, clinical features of TSC across all organ systems, comorbidities, and rare manifestations were collected, both retrospectively and prospectively at baseline and annually thereafter for up to 5 years. Given that this was a natural history study, participants were followed up based on clinical need, and no clinical, laboratory or formal 
TAND evaluations were mandated by the protocol. The terms and operationalization of TAND manifestations and 'levels' were defined as in the primary TAND publication [5].

The TOSCA registry was designed and conducted in accordance with the Guidelines for Good Clinical Practice and ethical principles outlined in the Declaration of Helsinki [29, 30]. Written informed consent, with prior endorsement by all local institutional review boards (human research ethics committees) was obtained from all participants, parents, or guardians prior to registry enrollment.

For the purposes of this manuscript, descriptive statistics were used to summarize TAND data. Frequency of TAND features were extracted and presented as percentage of individuals with available data (excluding non-reported or missing data). Intellectual ability was categorized as normal (IQ > 70), mild ID (IQ 51-70), moderate ID (IQ 36-50), severe ID (IQ 20-35), and profound ID (IQ $<20$ ), according to DSM-5/ICD-10 [31, 32]. Psychiatric disorders were defined according to the DSM-5/ICD-10. Age-based patterns of TAND (children vs adults) and the association between TAND and genotype (TSC1 vs TSC2) were analyzed using Chi-square test. The TOSCA study included data collection on all levels of TAND as outlined above and summarised in the primary TAND manuscript [5], apart from psychosocial characteristics, such as self-esteem, sibling, or family stressors, which were only included after the TOSCA database was set up.

\section{Results}

A total of 2216 participants (1154 females and 1062 males) with TSC were enrolled into the TOSCA registry from 170 sites across 31 countries at the data cut-off for the third interim analysis (September 30, 2015). The median age of the TOSCA cohort was 13 years (range, $<1-$ 71 ) with 1410 individuals $(63.6 \%)$ aged $\leq 18$ years.

\section{Overall TAND features}

Table 1 and Fig. 1 represent the frequencies of TAND features in the overall TOSCA cohort.

\section{Behavioural level}

The most common behavioural problems (reported in > $10 \%$ of participants) were overactivity (45\%), sleep difficulties (43.9\%), impulsivity (42.7\%), anxiety (33.3\%), mood swings (29.8\%), severe aggression (24.3\%), depressed mood (19.2\%), self-injury (15.5\%), and obsessions (14\%).

\section{Psychiatric level}

ASD was reported in 21.1\% (314/1486), ADHD in 19.1\% (268/1404), anxiety disorder in 9.7\% (133/1365), depressive disorder in 6.1\% (84/1371), and "other" psychiatric disorders were reported in $8.4 \%(115 / 1377)$ of participants. The median age at diagnosis of neuropsychiatric disorders were 5 years for ASD (mean, 7.8 years; range, $<1-40$ ), 6 years for ADHD (mean, 7.8 years; range, $<1-$ 38 ), 13.5 for anxiety disorder (mean, 17.4 years; range, < 1-50), 21 years for depressive disorder (mean, 24.3 years; range, 3-49), and 11 years for "other" psychiatric disorders (mean, 14.1 years; range, $<1-59$ ).

\section{Intellectual level}

An IQ assessment was available for 885 participants (39.9\%). Of these, 393 participants (44.4\%) had normal intellectual ability, while mild, moderate, severe, and profound degrees of ID were observed in $28.1 \%$ (249/ $885), 15.1 \%$ (134/885), 9.3\% (82/885), and 3.1\% (27/885), respectively.

\section{Academic and neuropsychological levels}

Academic/scholastic difficulties, classified as learning disorders in DSM-5, such as mathematics, reading, writing, or spelling, were noted in $58.6 \%(735 / 1254)$ of participants. Neuropsychological skills were formally assessed in 41.6\% (564/1355) of participants, and neuropsychological deficits (performance $<5$ th percentile) were identified in $55.7 \%(314 / 564)$ of those evaluated.

\section{TAND features in children vs adults}

Some differences were observed in the frequencies of TAND features between children (aged $\leq 18$ years), and adults (aged $>18$ years) (Table 2). At the behavioural level, the rates of overactivity and impulsivity were significantly higher for children than adults $(54.8 \%$ vs $21.4 \%$ and $46.7 \%$ vs $33.2 \%$ respectively, $p<0.001$ ), while rates of anxiety, mood swings, depressed mood, obsessions, psychosis and hallucinations were significantly higher in adults than children $(50.9 \%$ vs $25.8 \%$; $40.8 \%$ vs $25.2 \%$; $43.9 \%$ vs $8.2 \% ; 19.2 \%$ vs $11.8 \% ; 11.3 \%$ vs $3 \%$; $10.3 \%$ vs $0.6 \%$, respectively, $P<0.001$ for all except obsessions, $P<0.01$ ). Interestingly, some behavioural manifestations showed similar rates in children and adults. For instance, sleep difficulties and severe aggression were very similar between children and adults (Table 2). At the psychiatric level, ASD and ADHD were reported at higher rates in children than in adults $(23.1 \%$ vs $16.1 \% ; 22.4 \%$ vs $10.5 \% ; p=0.0029$ and $\mathrm{P}<0.001$ respectively), while rates of anxiety disorder and depressive disorder were higher in adults than in children $(16.8 \%$ vs $7 \% ; 16.3 \%$ vs $2.1 \%$ respectively; $P<0.001$ ). We observed no major differences in the rates of academic difficulties and neuropsychological skills between children and adults (Table 2). However, highly significant difference was observed between the rates of intellectual disability between children and adults (Table 2). 
Table 1 TAND Features in the Overall TOSCA Cohort $(N=2216)$

\begin{tabular}{|c|c|c|c|}
\hline TAND Features & $\begin{array}{l}\text { Individuals With Manifestation, } \\
\mathrm{n}(\%)^{\mathrm{a}}\end{array}$ & $\begin{array}{l}\text { Individuals With Available Data, } \\
\text { n (\%) }\end{array}$ & $\begin{array}{l}\text { Individuals with Data } \\
\text { Not Available*, n (\%) }\end{array}$ \\
\hline \multicolumn{4}{|l|}{ Behavioural level } \\
\hline Overactivity & $337(45.0)$ & 749 (33.8) & $1467(66.2)$ \\
\hline Sleep difficulties & 331 (43.9) & $754(34.0)$ & $1462(66.0)$ \\
\hline Impulsivity & $317(42.7)$ & $742(33.5)$ & $1474(66.5)$ \\
\hline Anxiety & $240(33.3)$ & $720(32.5)$ & $1496(67.5)$ \\
\hline Mood swings & $214(29.8)$ & $718(32.4)$ & $1498(67.6)$ \\
\hline Severe aggression & $183(24.3)$ & $754(34.0)$ & $1462(66.0)$ \\
\hline Depression mood & $139(19.2)$ & $724(32.7)$ & $1492(67.3)$ \\
\hline Self-injury & $117(15.5)$ & $755(34.1)$ & $1461(65.9)$ \\
\hline Obsessions & $100(14.0)$ & $714(32.2)$ & $1502(67.8)$ \\
\hline Psychosis & $40(5.5)$ & $725(32.7)$ & $1491(67.3)$ \\
\hline Hallucinations & $26(3.6)$ & $719(32.5)$ & $1497(67.5)$ \\
\hline \multicolumn{4}{|l|}{ Psychiatric level } \\
\hline ASD & $314(21.1)$ & $1486(67.1)$ & 730 (32.9) \\
\hline ADHD & $268(19.1)$ & $1404(63.4)$ & $812(36.6)$ \\
\hline Anxiety disorder & $133(9.7)$ & $1365(61.6)$ & 851 (38.4) \\
\hline Depressive disorder & $84(6.1)$ & $1371(61.9)$ & $845(38.1)$ \\
\hline \multicolumn{4}{|l|}{ Intellectual level } \\
\hline Normal & $393(44.4)$ & 885 (39.9) & $1331(60.1)$ \\
\hline Mild ID & $249(28.1)$ & 885 (39.9) & $1331(60.1)$ \\
\hline Moderate ID & $134(15.1)$ & 885 (39.9) & $1331(60.1)$ \\
\hline Severe ID & $82(9.3)$ & $885(39.9)$ & $1331(60.1)$ \\
\hline Profound ID & $27(3.1)$ & 885 (39.9) & $1331(60.1)$ \\
\hline \multicolumn{4}{|l|}{ Academic level } \\
\hline $\begin{array}{l}\text { Individuals ever had difficulties in academic } \\
\text { performance }\end{array}$ & 735 (58.6) & $1254(56.6)$ & $962(43.4)$ \\
\hline Individuals assessed for academic difficulties & $359(48.8)^{b}$ & NA & NA \\
\hline \multicolumn{4}{|l|}{ Neuropsychological level } \\
\hline $\begin{array}{l}\text { Individuals ever had any neuropsychological } \\
\text { skill assessed }\end{array}$ & $564(41.6)$ & $1355(61.1)$ & $861(38.9)$ \\
\hline Individuals with performance $<5$ th percentile & $314(55.7)^{c}$ & NA & NA \\
\hline
\end{tabular}

ASD autism spectrum disorder, $A D H D$ attention deficit hyperactivity disorder, ID intellectual disability, IQ intelligence quotient, NA not applicable, TAND TSCassociated neuropsychiatric disorders

*Missing data includes unknown option ticked for TAND features in eCRF by patient/investigator

apercentages calculated considering only available data and excluding missing data unless otherwise specified

bercentages calculated based on the number of individuals with reported academic difficulties as denominator

'Percentages calculated based on the number of individuals who had neuropsychological skill assessed as denominator

\section{TAND features by age bands}

Frequencies of all the TAND features by age bands at consent are depicted in Table 3 . The majority of TAND behavioural characteristics showed varying frequencies across age bands, but anxiety and depressed mood showed a clear pattern of increased frequency across increasing age bands. Interestingly, the rates of diagnoses of anxiety and depressive disorder showed a pattern that was not entirely consistent with the behavioural observations for anxiety and depressed mood. Severe and profound ID was reported at low rates in the youngest age group (3\%), increasing in the under 10-year olds (6.6 and 9.7\%), and ranging between $12.7-19.3 \%$ in the older age bands.

\section{TAND and genotype}

Molecular testing for genetic mutations was performed in 1000 participants (45.1\%). Of them, 197 had TSC1 mutations, 644 had TSC2 mutations, and 144 had no mutation identified (NMI). At the behavioural level, TSC2 mutations were associated only with significantly 


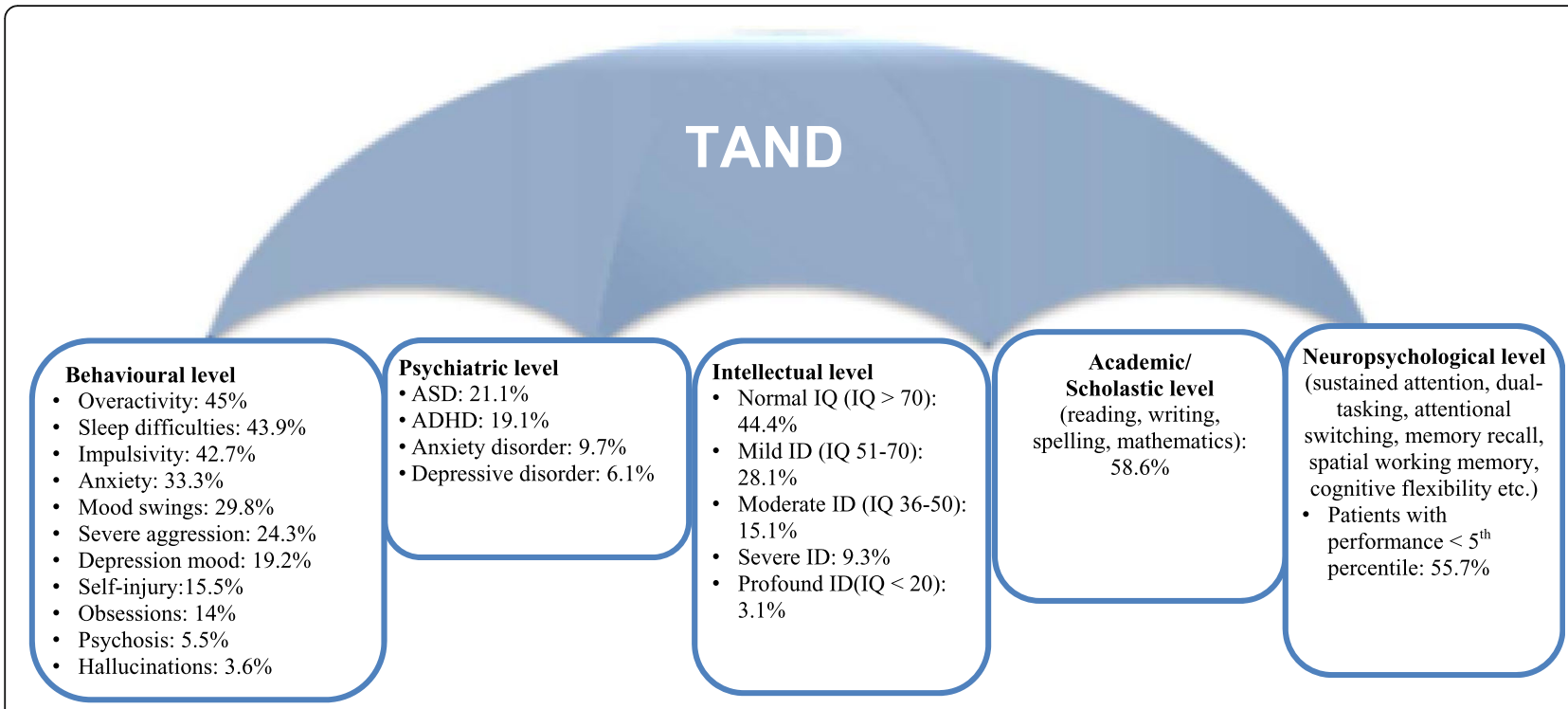

ASD, autism spectrum disorder; ADHD, attention deficit hyperactivity disorder; ID, intellectual disability; IQ, intelligence quotient; TAND, TSC-

associated neuropsychiatric disorders

Fig. 1 Summary of TAND Findings from the TOSCA Study $(N=2216)$

higher frequency than TSC1 for self-injury (15.8\% vs $6.3 \%, P=0.0288$; Table 4). At the psychiatric level, ASD was observed at significantly higher frequency in participants with TSC2 than those with TSC1 mutations (28.6\% vs $12.2 \%, P<0.001)$. ADHD, anxiety disorder and depressive disorder were not significantly different between the two genotypes, but it was interesting to observe that all three showed higher absolute frequencies in association with TSC1 rather than TSC2 (ADHD TSC $1=17.6 \%$; TSC2 $=16 \%, P=0.6881 ;$ Anxiety disorder TSC1 $=10.1 \%$; $T S C 2=8.6 \% ; P=0.7809$; Depressive dis orders $T S C 1=10 \%$; $T S C 2=5.2 \% ; P=0.0509$ ) (Table 4). The frequencies in behavioural and psychiatric manifestations of individuals with NMI ranged sometimes between and sometimes higher or lower than TSC1 and TSC2 (Table 4).

Of the 93 participants with TSC1 mutation who had been evaluated using IQ-type tests, 62 (66.7\%) had normal intellectual ability, 15 (16.1\%) had mild ID, 11 (11.8\%) had moderate ID, 5 (5.4\%) had severe ID, and no participant had profound ID. Among 293 participants with TSC2 mutation who had been evaluated using IQ-type tests, 123 (42\%) had normal intellectual ability, 75 (25.6\%) had mild ID, 57 (19.5\%) had moderate ID, 30 (10.2\%) had severe ID, and 8 (2.7\%) had profound ID. Significant difference was observed between TSC1 and TSC2 groups for IQ levels/categories. $(P=0.001$, Table 4$)$.

Academic/scholastic difficulties were more common in individuals with TSC2 mutation than those with TSC1 mutation (63.5\% vs $49.2 \% ; P=0.0051$, Table 4$)$. More individuals with TSC2 mutation had neuropsychological performance scores falling below the 5th percentile compared to those with TSC1 mutation (63\% vs $38.8 \%, P=$ 0.0024 ). Individuals with NMI showed IQ, academic and neuropsychological profiles in between the frequencies of the group with TSC1 and TSC2.

\section{Discussion}

The TOSCA registry allowed exploration of the frequency of a wide range of TAND features in the largest cohort of TSC reported to date. We set out to examine the overall TAND profile, to compare childhood and adult patterns, age-based patterns, and genotype-TAND correlations. Results showed lower rates of behavioural and psychiatric disorders than previously reported, but similar rates of ID $[3,6,8$, 12]. The very high rates of non-reported or missing data in this study (in excess of $60 \%$ for behavioural and intellectual levels) may, at least in part, have contributed to the lower rates observed. The rates of academic difficulties and neuropsychological deficits, reported in this study for the first time, were very high and suggested that between half and two-thirds of individuals with TSC will have difficulties in these two TAND levels. In spite of relatively similar rates of ID between children and adults, we observed a pattern of higher overactivity and impulsivity in children, and higher rates of anxiety and depressed mood in adults. Interestingly, some TAND characteristics such as sleep problems 
Table 2 TAND Features in Children vs Adults

\begin{tabular}{|c|c|c|c|}
\hline TAND Features & $\begin{array}{l}\text { Children }(\leq 18 \text { Years) With } \\
\text { Manifestation, }(n=1410) \\
\mathrm{n}(\%)\end{array}$ & $\begin{array}{l}\text { Adults (> } 18 \text { Years) With } \\
\text { Manifestation, }(n=806) \\
\mathrm{n}(\%)\end{array}$ & $p$ value \\
\hline \multicolumn{4}{|l|}{ Behavioural level $^{a}$} \\
\hline Overactivity & $290(54.8)$ & $47(21.4)$ & $<0.0001$ \\
\hline Sleep difficulties & $225(43.4)$ & $106(45.1)$ & 0.6531 \\
\hline Impulsivity & $244(46.7)$ & $73(33.2)$ & 0.0006 \\
\hline Anxiety & $130(25.8)$ & $110(50.9)$ & $<0.0001$ \\
\hline Mood swings & $128(25.2)$ & $86(40.8)$ & $<0.0001$ \\
\hline Severe aggression & $121(22.9)$ & $62(27.4)$ & 0.1850 \\
\hline Depressed mood & $41(8.2)$ & $98(43.9)$ & $<0.0001$ \\
\hline Self-injury & 73 (13.9) & $44(19.2)$ & 0.0625 \\
\hline Obsessions & $59(11.8)$ & $41(19.2)$ & 0.0085 \\
\hline Psychosis & $15(3.0)$ & $25(11.3)$ & $<0.0001$ \\
\hline Hallucinations & $3(0.6)$ & $23(10.3)$ & $<0.0001$ \\
\hline \multicolumn{4}{|l|}{ Psychiatric level $^{a}$} \\
\hline ASD & $246(23.1)$ & $68(16.1)$ & 0.0029 \\
\hline ADHD & $227(22.4)$ & $41(10.5)$ & $<0.0001$ \\
\hline Anxiety disorder & $68(7)$ & $65(16.8)$ & $<0.0001$ \\
\hline Depressive disorder & $21(2.1)$ & $63(16.3)$ & $<0.0001$ \\
\hline \multicolumn{4}{|l|}{ Intellectual level ${ }^{b}$} \\
\hline Normal IQ & $283(43.5)$ & $110(47.0)$ & \\
\hline Mild ID & $202(31)$ & $47(20.1)$ & \\
\hline Moderate ID & $101(15.5)$ & $33(14.1)$ & $0.0005^{e}$ \\
\hline Severe ID & $51(7.8)$ & $31(13.2)$ & \\
\hline Profound ID & $14(2.2)$ & $13(5.6)$ & \\
\hline \multicolumn{4}{|l|}{ Academic level } \\
\hline Individuals ever had difficulties in academic performance ${ }^{a}$ & $506(60.5)$ & $229(54.8)$ & 0.0517 \\
\hline Individuals assessed for academic difficulties ${ }^{c}$ & $273(54.0)^{c}$ & $86(37.6)^{c}$ & 0.0785 \\
\hline \multicolumn{4}{|l|}{ Neuropsychological level } \\
\hline Individuals ever had any neuropsychological skill assessed ${ }^{a}$ & $414(42.5)$ & $150(39.4)$ & 0.2926 \\
\hline Individuals with performance $<5$ th percentile ${ }^{d}$ & $235(56.8)^{d}$ & $79(52.7)^{d}$ & 0.5333 \\
\hline
\end{tabular}

$A S D$ autism spectrum disorder, $A D H D$ attention deficit hyperactivity disorder, ID intellectual disability, IQ intelligence quotient, TAND TSC-associated neuropsychiatric disorders

a Percentages calculated considering only available data and excluding missing data unless otherwise specified

bercentages calculated based on the number of individuals with IQ assessment available in each age group: $\leq 18$ years, $n=585 ;>18, n=234$ )

'Percentages calculated based on the number of individuals with reported academic difficulties as denominator

${ }^{\mathrm{d}}$ Percentages calculated based on the number of individuals who had neuropsychological skill assessed as denominator

${ }^{e}$ Chi-square test showing association between children and adults across all levels of IQ

and severe aggression remained high across all age bands, suggesting persistence of these difficulties across the lifespan. With regards to genotype-TAND correlations, we observed a genotype-intellectual phenotype correlation and a higher frequency of ASD in association with TSC2, similar to previous reports $[8,26]$. Interestingly, fewer other TAND-genotype correlations were observed. Self-injury, ASD, academic difficulties and neuropsychological deficits were the only other significant correlations with TSC2.
Given that all of these are known to be strongly correlated with intellectual level [12], and given the differences observed here in IQ groups, these results have to be treated with caution and should be explored in relation to matched or stratified IQ groups in future studies. We also observed a potential pattern of more depressed and anxious mood, and higher rates of anxiety and depressive disorders in association with TSC1 mutations. This was a novel observation not previously reported in the literature, but the same 
Table 3 TAND Features According to Age Bands (Based on Age at Consent)

\begin{tabular}{|c|c|c|c|c|c|c|c|}
\hline \multirow[t]{3}{*}{ TAND Features } & \multicolumn{7}{|c|}{ Age at Registry Consent, Years } \\
\hline & $\leq 2$ & $>2$ to $\leq 5$ & $>5$ to $\leq 9$ & $>9$ to $\leq 14$ & $>14$ to $\leq 18$ & $>18$ to $\leq 40$ & $>40$ \\
\hline & $n=283$ & $n=301$ & $n=335$ & $n=307$ & $n=184$ & $n=579$ & $n=227$ \\
\hline \multicolumn{8}{|l|}{ Behavioural level $^{a}$} \\
\hline Overactivity & $21(53.8)$ & $77(65.3)$ & $94(60.6)$ & $67(47.5)$ & $31(40.8)$ & $41(23.7)$ & $6(12.8)$ \\
\hline Sleep difficulties & $24(64.9)$ & $43(38.4)$ & $61(40.7)$ & $68(48.6)$ & $29(36.3)$ & $70(38.5)$ & $36(67.9)$ \\
\hline Impulsivity & $12(31.6)$ & $54(47.4)$ & $79(52.0)$ & $70(49.3)$ & $29(38.2)$ & $67(38.3)$ & $6(13.3)$ \\
\hline Anxiety & $2(5.6)$ & $24(21.2)$ & $33(22.9)$ & $45(33.3)$ & $26(34.2)$ & $74(44.6)$ & $36(72)$ \\
\hline Mood swings & $5(13.5)$ & $18(16.1)$ & $39(25.8)$ & $36(27.1)$ & $30(40.5)$ & $77(46.4)$ & $9(20)$ \\
\hline Severe aggression & $2(5.4)$ & $15(13.0)$ & $45(29.2)$ & $40(27.8)$ & $19(24.4)$ & $57(31.7)$ & $5(10.9)$ \\
\hline Depression mood & 0 & 0 & $10(6.9)$ & $17(12.7)$ & $14(18.7)$ & $68(40.2)$ & $30(55.6)$ \\
\hline Self-injury & $3(7.9)$ & $9(7.8)$ & $28(18.7)$ & $23(16.1)$ & $10(12.7)$ & $37(20.6)$ & $7(14.3)$ \\
\hline Obsessions & $2(5.6)$ & $7(6.3)$ & $15(10.3)$ & $22(16.3)$ & $13(17.6)$ & $33(19.9)$ & $8(17.0)$ \\
\hline Psychosis & 0 & $2(1.8)$ & $4(2.8)$ & $7(5.2)$ & $2(2.6)$ & $22(12.6)$ & $3(6.3)$ \\
\hline Hallucinations & 0 & 0 & 0 & $3(2.3)$ & 0 & $21(11.9)$ & $2(4.3)$ \\
\hline \multicolumn{8}{|l|}{ Psychiatric level ${ }^{a}$} \\
\hline ASD & $18(10.8)$ & $49(22.9)$ & $73(26.2)$ & $68(26.3)$ & $38(26)$ & 65 (18.6) & $3(4.2)$ \\
\hline $\mathrm{ADHD}$ & $11(7.1)$ & $50(24.2)$ & $82(31.1)$ & $61(24.5)$ & $23(16.7)$ & $39(12.1)$ & $2(2.9)$ \\
\hline Anxiety disorder & $1(0.6)$ & $8(3.9)$ & $15(5.9)$ & $31(13.1)$ & $13(10.4)$ & $51(16.1)$ & $14(19.7)$ \\
\hline Depressive disorder & 0 & $3(1.4)$ & $2(0.8)$ & $8(3.4)$ & $8(6.3)$ & $44(14.2)$ & $19(25)$ \\
\hline \multicolumn{8}{|l|}{ Intellectual level| } \\
\hline Normal IQ & $37(56.1)$ & $72(52.9)$ & $74(39.8)$ & $64(37.9)$ & $36(38.3)$ & $82(42.7)$ & $28(66.7)$ \\
\hline Mild ID & $18(27.3)$ & $38(27.9)$ & $58(31.2)$ & $56(33.1)$ & $32(34.0)$ & $43(22.4)$ & $4(9.5)$ \\
\hline Moderate ID & $9(13.6)$ & $17(12.5)$ & $36(19.4)$ & $25(14.8)$ & $14(14.9)$ & $30(15.6)$ & $3(7.1)$ \\
\hline Severe ID & $1(1.5)$ & $9(6.6)$ & $13(7.0)$ & $18(10.7)$ & $10(10.6)$ & $27(14.1)$ & $4(9.5)$ \\
\hline Profound ID & $1(1.5)$ & 0 & $5(2.7)$ & $6(3.6)$ & $2(2.1)$ & $10(5.2)$ & $3(7.1)$ \\
\hline \multicolumn{8}{|l|}{ Academic level } \\
\hline $\begin{array}{l}\text { Individuals ever had difficulties in } \\
\text { academic performance }^{\mathrm{a}}\end{array}$ & $1(1.3)$ & $48(36.9)$ & $167(69.3)$ & $193(75.7)$ & $97(73.5)$ & $195(59.6)$ & $34(37.4)$ \\
\hline $\begin{array}{l}\text { Individuals assessed for academic } \\
\text { difficulties }^{c}\end{array}$ & 0 & $20(41.7)$ & $93(55.7)$ & $103(53.4)$ & $57(58.8)$ & 77 (39.5) & $9(26.5)$ \\
\hline \multicolumn{8}{|l|}{ Neuropsychological level } \\
\hline $\begin{array}{l}\text { Individuals ever had any } \\
\text { neuropsychological skill assessed }\end{array}$ & $31(20.4)$ & $69(32.4)$ & $121(48.2)$ & $124(53.2)$ & $69(55.2)$ & $129(42.7)$ & $21(26.6)$ \\
\hline $\begin{array}{l}\text { Individuals with performance }<5 \text { th } \\
\text { percentile }^{d}\end{array}$ & $12(38.7)$ & $35(50.7)$ & $69(57.0)$ & $78(62.9)$ & $41(59.4)$ & $72(55.8)$ & $7(33.3)$ \\
\hline
\end{tabular}

ASD autism spectrum disorder, $A D H D$ attention deficit hyperactivity disorder, $I Q$ intelligence quotient, ID intellectual disability, TAND TSC-associated

neuropsychiatric disorders. Values are expressed as $\mathrm{n}(\%)$

${ }^{a}$ Percentages calculated considering only available data and excluding missing data

${ }^{\mathrm{b}}$ Percentages calculated considering individuals with IQ assessment available in each age group: $\leq 2$ years $(n=66) ;>2$ to $\leq 5$ years $(n=136) ;>5$ to $\leq 9$ ( $\left.n=186\right) ;>$

9 to $\leq 14(n=169) ;>14$ to $\leq 18(n=94) ;>18$ to $\leq 40(n=192) ;>40(n=42)$

'Percentages calculated based on the number of individuals with reported academic difficulties as denominator

dPercentages calculated based on the number of individuals who had neuropsychological skill assessed as denominator

caveat in relation to IQ as potential confounder requires exploration in future studies. The TAND profile of individuals with NMI was also a novel finding. Intellectual, academic and neuropsychological profiles seemed to fall between the frequencies of those with TSC1 and TSC2 mutations, mapping onto intellectual findings previously reported $[8,26]$.
However, the same pattern was not seen in behavioural and psychiatric manifestations.

About 7\% of individuals in the general population are expected to have clinically significant behavioural problems [33]. However, much higher rates of behavioural difficulties are reported in patients with TSC [7]. In a 
Table 4 TAND Features by Genotype

\begin{tabular}{|c|c|c|c|c|}
\hline TAND Features & $\begin{array}{l}\text { Individuals With TSC1 } \\
\text { Mutation } \\
(n=197) \\
\mathrm{n}(\%)^{\mathrm{a}}\end{array}$ & $\begin{array}{l}\text { Individuals With TSC2 } \\
\text { Mutation, } \\
(n=644) \\
\mathrm{n}(\%)^{\mathrm{a}}\end{array}$ & $\begin{array}{l}\text { Individuals With no TSC } \\
\text { Mutation Identified (NMI), } \\
(n=144) \\
\mathrm{n}(\%)^{\mathrm{a}}\end{array}$ & $\begin{array}{l}\text { Statistical difference } \\
\text { between TSC1 and TSC2 } \\
p \text { Value }\end{array}$ \\
\hline \multicolumn{5}{|l|}{ Behavioural level } \\
\hline Overactivity & $27(40.9)$ & $112(43.4)$ & $24(45.3)$ & 0.8788 \\
\hline Sleep difficulties & $31(48.4)$ & $129(50.6)$ & $30(54.5)$ & 0.5656 \\
\hline Impulsivity & $32(49.2)$ & $107(41.6)$ & $23(45.1)$ & 0.1773 \\
\hline Anxiety & $24(38.7)$ & $82(33.6)$ & $17(34.0)$ & 0.5519 \\
\hline Mood swings & $14(21.5)$ & 64 (26.6) & $15(29.4)$ & 0.4907 \\
\hline Severe aggression & $14(21.2)$ & $56(21.5)$ & $11(20.8)$ & 0.9290 \\
\hline Depression mood & $15(24.2)$ & $46(18.7)$ & $12(23.5)$ & 0.2651 \\
\hline Self-injury & $4(6.3)$ & $41(15.8)$ & $8(14.5)$ & 0.0288 \\
\hline Obsessions & $8(13.1)$ & $35(14.2)$ & $8(16.0)$ & 0.9140 \\
\hline Hallucinations & $3(4.8)$ & $7(2.8)$ & $2(3.9)$ & 0.3960 \\
\hline Psychosis & $4(6.5)$ & $9(3.6)$ & $3(5.8)$ & 0.2865 \\
\hline \multicolumn{5}{|l|}{ Psychiatric level } \\
\hline ASD & $18(12.2)$ & $138(28.6)$ & $17(17.5)$ & $<0.0001$ \\
\hline ADHD & $24(17.6)$ & $72(16.0)$ & $14(14.9)$ & 0.6881 \\
\hline Anxiety disorder & $14(10.1)$ & $38(8.6)$ & $8(9.2)$ & 0.7809 \\
\hline Depressive disorder & $14(10.0)$ & $23(5.2)$ & $7(8.0)$ & 0.0509 \\
\hline \multicolumn{5}{|l|}{ Intellectual level ${ }^{b}$} \\
\hline Normal IQ & $62(66.7)$ & $123(42.0)$ & $41(64.1)$ & \\
\hline Mild ID & $15(16.1)$ & 75 (25.6) & $14(21.9)$ & \\
\hline Moderate ID & $11(11.8)$ & $57(19.5)$ & $3(4.7)$ & $0.001^{f}$ \\
\hline Severe ID & $5(5.4)$ & $30(10.2)$ & $6(9.4)$ & \\
\hline Profound ID & 0 & $8(2.7)$ & 0 & \\
\hline \multicolumn{5}{|l|}{ Academic level } \\
\hline $\begin{array}{l}\text { Individuals ever had difficulties } \\
\text { in academic performance }\end{array}$ & $63(49.2)$ & $240(63.5)$ & $53(58.2)$ & 0.0051 \\
\hline $\begin{array}{l}\text { Individuals assessed for } \\
\text { academic difficulties }\end{array}$ & $34(54.0)^{c}$ & $132(55.0)^{c}$ & $25(47.2)^{c}$ & 0.5391 \\
\hline \multicolumn{5}{|l|}{ Neuropsychological level } \\
\hline $\begin{array}{l}\text { Individuals ever had any } \\
\text { neuropsychological skill } \\
\text { assessed }\end{array}$ & $67(51.1)$ & $216(49.4)$ & $46(51.1)$ & 0.7697 \\
\hline $\begin{array}{l}\text { Individuals with performance } \\
<5 \text { th percentile }\end{array}$ & $26(38.8)^{d}$ & $136(63.0)^{d}$ & $19(41.3)^{d}$ & 0.0024 \\
\hline
\end{tabular}

ASD autism spectrum disorder, ADHD attention deficit hyperactivity disorder, ID intellectual disability, IQ intelligence quotient, TAND TSC-associated neuropsychiatric disorders

*Molecular testing for genetic mutations was performed in 1000 (45.1\%) individuals. Of these, $644(64.4 \%)$ had a TSC2 gene mutation, 197 (19.7\%) had a TSC1 gene mutation, 6 had both TSC1 and TSC2 gene mutations and $144(14.4 \%)$ had no mutations. Data were not available for 9 individuals

aPercentages calculated considering only available data and excluding missing data unless otherwise specified

${ }^{b}$ Percentages calculated considering individuals with IQ assessment available in each group: Individuals with TSC1 mutation, $n=93$; individuals with TSC2 mutation, $n=293$ )

cPercentages calculated based on the number of individuals with reported academic difficulties as denominator

dPercentages calculated based on the number of individuals who had neuropsychological skill assessed as denominator

${ }^{\mathrm{e}}$ TSC1 vs TSC2

${ }^{\mathrm{f}} \mathrm{Chi}$-square test showing association between children and adults across all levels of IQ

pilot validation study of the TAND checklist, all the participants $(n=62)$ had reported at least one lifetime TAND behavioural difficulty, $97 \%$ had $\geq 2$ behavioural difficulties and $89 \%$ reported $\geq 6$ behavioural difficulties [6]. The findings in this large-scale international study confirm the high rates of a wide range of behavioural 
problems in TSC. The comparison between children and adults showed a pattern of lower overactive/impulsive behaviours in adults but higher anxiety or depressed mood. These findings map well onto typical age-based expectations in psychopathology $[8,9,12]$. However, our results also highlighted the fact that behavioural difficulties occurred across all ages in individuals with TSC. These findings underline the importance of expecting and evaluating for a changing profile of TAND difficulties from childhood into adulthood, as recommended in TAND assessment guidelines [2, 34, 35].

Among the psychiatric problems associated with TSC, ASD, and ADHD are the most common neurodevelopmental disorders in children, and anxiety/mood disorders the most common in adults [8]. The variable rates of ASD (17-68\%) and ADHD (30-60\%) reported in earlier studies can be understood based on different study methodologies, diagnostic criteria used, and level of intellectual ability of participants $[7,8,36]$. In this study, ASD and ADHD were reported in $21.1 \%$ and $19.1 \%$ of participants, respectively. As highlighted in our baseline paper [27] the diagnosis of ASD, in particular, was made very late (mean age, 7.8 years; median age, 5 years; range, $0-38$ years) [28]. In spite of very high rates of anxiety and depressed mood symptoms in the cohort, the rates of diagnoses of anxiety disorders or depressive disorders were surprisingly low in our study (anxiety disorder, 9.7\%; depressive disorder, $6.1 \%)$. Taking together the high rates of non-reported or missing data, late ages of diagnoses and frequencies observed in our cohort, we suggest that psychiatric disorders are underdiagnosed and potentially diagnosed late in individuals with TSC. The low rates of ASD and ADHD observed in adults here, may suggest a cohort effect where adults were not assessed for developmental disorders in the past decades.

In line with previous reports, $[8,26,37]$ the TOSCA registry showed a genotype-intellectual phenotype pattern suggesting a greater likelihood of ID in participants with TSC2 than those with TSC1 mutations. However, it was also important to note that only $66.7 \%$ of those with TSC1 had normal intellectual ability, suggesting that a third of individuals with TSC1 may have ID. Similarly, even though TSC2 mutations were more likely to be associated with ID, $42 \%$ of all individuals with TSC 2 mutations had normal intellectual ability. Our findings therefore reinforce the message that genotype (TSC1 vs TSC2) is not a clinically helpful predictor of intellectual ability at an individual level [26].

The differences between those with TSC1 and TSC2 mutations observed in other aspects of TAND were of interest, particularly as all previous genotype-phenotype studies have suggested a more "severe" phenotype associated with TSC2 [38]. The possibility that specific aspects of TAND may be more likely in association with
TSC1 is therefore a potentially important observation. We acknowledge that a TSC1 vs TSC2 differentiation may be highly oversimplistic, given that specific TSC mutations may be associated with very different functional consequences at a biochemical level [16, 26].

The challenge around unreported and missing TAND data in this study was significant. Fewer than $40 \%$ of behavioural data were available and only $39.9 \%$ of participants in the TOSCA registry received an evaluation of their intellectual ability. The overall rates of ID were consistent with previous studies, $[8,12]$ but we did not observe a bimodal distribution of intellectual ability as previously reported [23, 25, 39, 40]. Given that only about half of the TOSCA cohort received a formal evaluation for IQ, it is possible that more severely impaired individuals may not have been referred for an assessment of their intellectual or developmental quotient (as was done in the population-based study that observed the clear bimodal pattern) [39]. Academic data were not reported or were missing in $43.4 \%$ of the cohort and $38.9 \%$ were not reported or were missing regarding neuropsychological skills. Only $48.8 \%$ of those with academic difficulties ever received evaluations, and only 41.6\% were evaluated for neuropsychological deficits. Whilst the very high rates of academic and neuropsychological deficits in TSC were a novel finding in the TOSCA registry and underlines the recommendation that all children with TSC should receive evaluation of their academic and neuropsychological needs, $[2,35]$ the very low proportion assessed raises significant clinical concern.

\section{Conclusions}

Together, findings from the TOSCA registry emphasize the magnitude of neuropsychiatric disorders in TSC, which has an enormous impact on quality of life of individuals with TSC and their families. However, there was a high proportion of non-reported or missing data, which may have impacted the overall findings of the study. Due to the observational nature of the registry, only data already available from clinical practice were collected. Moreover, considering the disease complexity and the fact that individuals with TSC were not always followed for all disease manifestations by the site involved in the registry, ensuring report of all disease manifestations of each participant was a major challenge. We therefore acknowledge the potential ascertainment biases that may come with large-scale clinic-based natural history studies such as this one.

There is clearly a highly dynamic interaction between development, genotype, intellectual ability, epilepsy, anti-epilepsy and other pharmacological treatments, and environment in TSC. Future studies should therefore aim to examine these interrelations in an integrated way 
using suitable multilevel computational modelling. We also acknowledge that further evaluations will be required to examine TAND in relation to intellectual level and sex. In addition, efforts are underway to determine if there may be "natural TAND clusters" consisting of natural groupings of TAND characteristics within and between individuals with TSC across levels of TAND [7, 13]. The TOSCA cohort may provide a powerful dataset to examine this possibility further.

In spite of the limitations inherent to a large-scale natural history study, results provide strong data to encourage clinicians to evaluate for neuropsychiatric comorbidity in all children and adults with TSC. The 2012 TSC surveillance and management guidelines recommend annual screening for TAND [34]. A simple tool called the TAND Checklist has been developed and validated in a pilot study that could provide easy guidance to healthcare professionals in assessing neuropsychiatric difficulties in each individual with TSC $[3,5,6]$.

\section{Abbreviations}

ADHD: Attention deficit hyperactivity disorder; ASD: Autism spectrum disorders; ID: Intellectual disability; IQ: Intelligence quotient; TAND: TSCassociated neuropsychiatric disorders; TOSCA: TuberOus SClerosis registry to increase disease Awareness; TSC: Tuberous sclerosis complex

\section{Acknowledgements}

We thank patients and their families, investigators, and staff from all the participating sites. We thank Manojkumar Patel, Novartis Healthcare Pvt. Ltd. for providing medical editorial assistance with this manuscript. TOSCA Investigators

Japan: Nobuo Shinohara, Shigeo Horie, Masaya Kubota, Jun Tohyama, Katsumi Imai, Mari Kaneda, Hideo Kaneko, Yasushi Uchida, Tomoko Kirino, Shoichi Endo, Yoshikazu Inoue, Katsuhisa Uruno; Turkey: Ayse Serdaroglu, Zuhal Yapici, Banu Anlar, Sakir Altunbasak; Russia: Olga Lvova, Oleg Valeryevich Belyaev, Oleg Agranovich, Elena Vladislavovna Levitina, Yulia Vladimirovna Maksimova, Antonina Karas; China: Yuwu Jiang, Liping Zou, Kaifeng Xu, Yushi Zhang, Guoming Luan, Yuqin Zhang, Yi Wang, Meiling Jin, Dingwei Ye, Weiping Liao, Liemin Zhou, Jie Liu, Jianxiang Liao, Bo YAN, Yanchun Deng, Li Jiang, Zhisheng Liu, Shaoping Huang, Hua Li; Korea: Kijoong Kim; Taiwan: Pei-Lung Chen, Hsiu-Fen Lee, Jeng-Dau Tsai, ChingShiang Chi, Chao-Ching Huang; Australia: Kate Riney, Deborah Yates, Patrick Kwan; Thailand: Surachai Likasitwattanakul, Charcrin Nabangchang, Lunliya Thampratankul Krisnachai Chomtho, Kamornwan Katanyuwong, Somjit Sriudomkajorn; South Africa: Jo Wilmshurst; Israel: Reeval Segel, Tal Gilboa, Michal Tzadok, Aviva Fattal- Valevski; Greece: Panagiotis Papathanasopoulos, Antigone Syrigou Papavasiliou, Stylianos Giannakodimos, Stylianos Gatzonis, Evangelos Pavlou, Meropi Tzoufi; Netherlands: A.M.H. Vergeer; Belgium: Marc Dhooghe, Hélène Verhelst, Filip Roelens, Marie Cecile Nassogne, Pierre Defresne, Liesbeth De Waele, Patricia Leroy, Nathalie Demonceau, Benjamin Legros, Patrick Van Bogaert, Berten Ceulemans, Lina Dom; France: Pierre Castelnau, Anne De Saint Martin, Audrey Riquet, Mathieu Milh, Claude Cances, Jean-Michel Pedespan, Dorothee Ville, Agathe Roubertie, Stéphane Auvin, Patrick Berquin, Christian Richelme, Catherine Allaire, Sophie Gueden, Sylvie Nguyen The Tich, Bertrand Godet; Spain: Maria Luz Ruiz Falco Rojas, Jaume Campistol Planas, Antonio Martinez Bermejo, Patricia Smeyers Dura, Susana Roldan Aparicio, Maria Jesus Martinez Gonzalez, Javier Lopez Pison, Manuel Oscar Blanco Barca, Eduardo Lopez Laso, Olga Alonso Luengo, Francisco Javier Aguirre Rodriguez, Ignacio Malaga Dieguez, Ana Camacho Salas, Itxaso Marti Carrera, Eduardo Martinez Salcedo, Maria Eugenia Yoldi Petri, Ramon Cancho Candela; Portugal: Ines da Conceicao Carrilho, Jose Pedro Vieira, José Paulo da Silva Oliveira Monteiro, Miguel Jorge Santos de Oliveira Ferreira Leao, Catarina Sofia Marceano Ribeiro Luis, Carla Pires Mendonca; Lithuania: Milda Endziniene; Latvia: Jurgis Strautmanis; Estonia: Inga Talvik; Italy: Maria Paola Canevini, Antonio Gambardella, Dario Pruna, Salvatore Buono, Elena
Fontana, Bernardo Dalla Bernardina; Romania: Carmen Burloiu, Iuliu Stefan Bacos Cosma, Mihaela Adela Vintan, Laura Popescu; Czech Republic: Karel Zitterbart; Slovakia: Jaroslava Payerova, Ladislav Bratsky, Zuzana Zilinska; Austria: Ursula Gruber-Sedlmayr, Matthias Baumann, Edda Haberlandt, Kevin Rostasy, Ekaterina Pataraia; United Kingdom: Frances Elmslie, Clare Ann Johnston, Pamela Crawford; Denmark: Peter Uldall; Sweden: Paul Uvebrant, Olof Rask; Norway: Marit Bjoernvold, Eylert Brodtkorb, Andreas Sloerdahl, Ragnar Solhoff, Martine Sofie Gilje Jaatun; Poland: Marek Mandera, Elzbieta Janina Radzikowska, Mariusz Wysocki; Germany: Michael Fischereder, Gerhard Kurlemann, Bernd Wilken, Adelheid Wiemer-Kruel, Klemens Budde, Klaus Marquard, Markus Knuf, Andreas Hahn, Hans Hartmann, Andreas Merkenschlager, Regina Trollmann.

\section{Funding}

The study was funded by Novartis Pharma AG. Novartis has contributed to the study design, data analysis, and the decision to publish. Novartis authors reviewed the draft for submission.

\section{Availability of data and materials}

Novartis supports the publication of scientifically rigorous analysis that is relevant to patient care, regardless of a positive or negative outcome. Qualified external researchers can request access to anonymized patientlevel data, respecting patient informed consent, contacting study sponsor authors. The protocol can be accessed through EnCePP portal http:// www.encepp.eu/ (EU PAS Register Number EUPAS3247).

\section{Authors' contributions}

PJdV Designing the study, data interpretation, drafting, revising, final review, and approval of the manuscript. EB Designing the study, patient accrual, clinical care, data interpretation, drafting, revising, final review, and approval of the manuscript. MPB Designing the study, patient accrual, clinical care, data interpretation, drafting, revising, final review, and approval of the manuscript. TC Designing the study, data interpretation, drafting, revising, final review, and approval of the manuscript. VC Designing the study, data interpretation, drafting, revising, final review, and approval of the manuscript. PC Designing the study, patient accrual, clinical care, data interpretation, drafting, revising, final review, and approval of the manuscript. MD Designing the study, patient accrual, clinical care, data interpretation, drafting, revising, final review, and approval of the manuscript. LD'A. Designing the study, patient accrual, trial management, data collection, data analysis, data interpretation, drafting, revising, final review, and approval of the manuscript. GBdA. Designing the study, data interpretation, drafting, revising, final review, and approval of the manuscript. JCF Designing the study, patient accrual, clinical care, data interpretation, drafting, revising, final review, and approval of the manuscript. MF Designing the study, patient accrual, clinical care, data interpretation, drafting, revising, final review, and approval of the manuscript. CF Designing the study, data interpretation, drafting, revising, final review, and approval of the manuscript. CH Designing the study, patient accrual, clinical care, data interpretation, drafting, revising, final review, and approval of the manuscript. SJ Designing the study, patient accrual, clinical care, data interpretation, drafting, revising, final review, and approval of the manuscript. JCK Designing the study, patient accrual, clinical care, data interpretation, drafting, revising, final review, and approval of the manuscript. JAL Designing the study, patient accrual, clinical care, data interpretation, drafting, revising, final review, and approval of the manuscript. AM Designing the study, patient accrual, clinical care, data interpretation, drafting, revising, final review, and approval of the manuscript. RM Designing the study, patient accrual, data analysis, data interpretation, drafting, revising, final review, and approval of the manuscript. RN Designing the study, patient accrual, clinical care, data interpretation, drafting, revising, final review, and approval of the manuscript. FOC Designing the study, data interpretation, drafting, revising, final review, and approval of the manuscript. JQ Designing the study, data interpretation, drafting, revising, final review, and approval of the manuscript. VS Designing the study, patient accrual, clinical care, data interpretation, drafting, revising, final review, and approval of the manuscript. MS Designing the study, patient accrual, clinical care, data interpretation, drafting, revising, final review, and approval of the manuscript. SS Designing the study, trial statistician, data analysis, data interpretation, drafting, revising, final review, and approval of the manuscript. YT Designing the study, data interpretation, drafting, revising, final review, and approval of the manuscript. RT Designing the study, patient accrual, clinical care, data interpretation, 
drafting, revising, final review, and approval of the manuscript. SY Designing the study, data interpretation, drafting, revising, final review, and approval of the manuscript. BZ Designing the study, patient accrual, clinical care, data interpretation, drafting, revising, final review, and approval of the manuscript. ACJ Designing the study, patient accrual, clinical care, data interpretation, drafting, revising, final review, and approval of the manuscript. All authors read and approved the final manuscript.

\section{Ethics approval and consent to participate}

All patients (or their legal representatives) provided written informed consent before enrolling in the TOSCA disease registry. The study was designed, implemented, and reported in accordance with the principles of Good Clinical Practice, Good Pharmacoepidemiology Practices of the International Society for Pharmacoepidemiology (ISPE 2008), the STROBE (Strengthening and Reporting of Observational Studies in Epidemiology) guidelines, and the ethical principles laid down in the Declaration of Helsinki, and all local regulations. The study protocol and all amendments were reviewed and approved (if applicable) by independent ethics committee/ institutional review board for each center: National Hospital Organization Central Ethics Committee; Gazi University Clinical Research Ethics Committee; Independent Multidisciplinary Committee on Ethical Review of Clinical Trials; Peking Union Medical College Hospital; Commissie Medische Ethiek UZ Brussel; CNIL (Commission National de I'Informatique et des Libertés), CCTIRS (Comité Consultatif sur le traitement de l'information en matière de recherche dans le domaine de la santé); Comité Etico Investigación Clínica de Euskadi (CEIC-E); Consejeria de Salud y Bienestar Social, Dirección General de Calidad, Investigación, Desarrollo e Innovación, Comité Coordinador de Ética de la Investigación Biomédica de Andalucía; Research Ethics Committee of the University of Tartu (UT REC); Ethikkommission der Medizinischen Universität Graz; North Wales REC - West; Regionala Etikprövningsnämnden i Göteborg; REK - Regionale komiteer for medisinsk og helsefaglig forskningsetikk; Komisja Bioetyczna przy Instytucie "Pomnik Centrum Zdrowia Dziecka"; Ethikkommission bei der Ludwig-Maximilians-Universitat München; Hokkaido University Hospital Independent clinical research Institutional Ethics Committee; Medical Juntendo University Institutional Ethics Committee; National Center for Chile Health and Deveropment of IRB; Osaka University Hospital of IRB; Ethics Committee at Moscow Institute of Pediatrics and Pediatric Surgery; Peking University First Hospital; Sanbo Brain Hospital Capital Medical University; Tianjin Children's Hospital; Childrens Hospital Of Fudan University; Zhongshan Hospital Fudan University; Fudan University Shanghai Cancer Center; The Second Affiliated Hospital of Guangzhou Medical University; The First Affiliated Hospital, Sun Yan-Sen University; The First Affiliated Hospital Of Guangzhou Medical University; Shenzhen Children's Hospital; West China Hospital, Sichuan University; Xijing Hospital; Children's Hospital of Chongqing Medical University; Wuhan Children's Hospital; The second affiliated hospital of Xi'an jiaotong university; Guangdong 999 brain hospital; Seoul National University Hospital Institutional Review Board; National Taiwan University Hospital (NTUH) Research Ethics Committee (REC); Institutional Review Board of the Taichung Veterans General Hospital; Institutional Review Board of Chung Shan Medical University Hospital; Institutional Review Board, Tungs' Taichung MetroHarbor Hospital; Institutional Review Board of National Cheng Kung University Hospital; Metro South Human Research Ethics Committee; Sydney Children's Hospital Network Human Research Ethics Committee; St Vincents Hospital Human Research Ethics Committee; Royal Melbourne Hospital Human Research Ethics Committee; Siriraj Institutional Review Board; The Institutional Review board, Faculty of Medicine, Chulalongkorn University, 3rd Floor, Ananthamahidol Building, King Chulalongkorn Memorial Hospital; The committee on Human Rights Related to Research Involving Human Subjects; Institutional Review board, Royal Thai Army Medical Department IRB RTA, 5th Floor, Phramongkutklaowejvitya Building, Phramongkutklao College of Medicine; Research Ethics Committee, Faculty of Medicine, Chiang Mai University; Research and Development, Queen Sirikit National Institute of Child Health; Human Research Ethics Committee, Faculty of Health Sciences, University of Cape Town; Shaare Zedek Meidcla center Helsinki comittee; Sheba Medical center Helsinki comittee; Tel Aviv Sourasly Medical center Helsinki comittee; General University Hospital of Patras Ethics Committee; Pendeli Children's Hospital Ethics Committee; General University Hospital of Athens "G. Gennimatas" Ethics Committee; Evaggelismos General Hospital Ethics Committee; General University Hospital of Thessaloniki "AHEPA" Ethics Committee; General University Hospital of Ionnina Ethics Committee; METC UMC Utrecht; Direcció General de Regulació, Planificació i Recursos Sanitaris;
Comité Ético de Investigación Clínica del Hospital Universitario Vall d'Hebron de Barcelona, Generalitat de Catalunya.Departament de Salut; Comité Ético de Investigación Clínica Hospital Universitario La Paz; Dirección General de Ordenación e Inspección, Consejería de Sanidad Comunidad de Madrid, Servicios de Control Farmacéutico y Productos Sanitarios; Comité Etico Investigación Clínica del Hospital Universitario y Politécnico de La Fe; Dirección General de Farmàcia i Productes Sanitaris, Generalitat de Valencia; Comité de Ética de la Investigación de Centro de Granada; Instituto Aragonés de Ciencias de la Salud (IACS); Comité Etico Investigación Clínica Regional del Principado de Asturias;" Comité Etico Investigación Clínica Hospital 12 de Octubre; Comité Etico Investigación Clínica Hospital Universitario Virgen de la Arrixaca; Sección de Ordenación e Inspección Farmacéutica Departamento de Salud; Comité Ético de Investigación Clínica del Hospital Universitario del Río Hortega de Valladolid; Comissão de Ética para a Saúde (CES), Centro Hospitalar de Lisboa Ocidental, EPE; Comissão de Ética para a Saúde (CES), Centro Hospitalar do Porto, E.P.E; Comissão de Ética para a Saúde (CES), Centro Hospitalar Lisboa Central, EPE; Comissão de Ética para a Saúde (CES), Hospital Garcia de Orta, EPE; Comissão de Ética para a Saúde (CES), Centro Hospitalar de São João, EPE; Comissão de Ética para a Saúde (CES), Hospital Professor Doutor Fernando Fonseca, EPE; Comissão de Ética para a Saúde (CES), Centro Hospitalar do Algarve, EPE (Unidade de Faro); LUHS Kaunas Regional Biomedical Research Ethics Committee; Paula Stradina klīniskās universitātes slimnīcas, Attīstības biedrības Klīniskās izpētes Ētikas komiteja, Ethics Committee for Clinical Research; Komisija Republike Slovenije za medicinsko etiko; Comitato Etico Indipendente Presso La Fondazione Ptv Policlinico Tor Vergata Di Roma; Comitato Etico Regione Calabria Sezione Centro c/o A.O.U. Mater Domini Di Catanzaro; Comitato Etico Azienda Ospedaliera Universitaria Di Cagliari; Comitato Etico Cardarelli-Santobono c/o Ao Cardarelli; Comitato Etico Per La Sperimentazione Clinica Delle Province Di Verona E Rovigo, Presso Aoui Verona; Eticka Komise Fn Brno; Eticka Komisia Dfnsp Bratislava; Eticka Komisia Pri Dfn Kosice; Eticka Komisia Bratislavskeho Samospravneho Kraja; Comisia Națională de Bioetică a Medicamentului și a Dispozitivelor Medicale; Comitato Etico Milano area 1 c/o ASST FBF Sacco - P.O. L. Sacco; Comité de Ética de la Investigación de Centro Hospital Universitario Virgen del Rocío; Comité Ético de Investigación Clínica Fundació Sant Joan de Déu Generalitat de Catalunya. Departament de Salut; Comité Ético de Investigación Clínica Hospital Infantil Universitario Niño Jesús; Consejería de Sanidad Dirección General de Salus Pública Junta de Castilla León; Dirección General de Asistencia Sanitaria, Consejería de Sanidad Gobierno del Principado de Asturias; Dirección General de Planificación, Ordenación Sanitaria y Farmacéutica e Investigación, Consejeria de Sanidad y Política Social Región de Murcia; Ethics Committee at Moscow Institute of Pediatrics and Pediatric Surgery; Paula Stradina klīniskās universitātes slimnīcas, Attīstības biedrības Klīniskās izpētes Ētikas komiteja, Ethics Committee for Clinical Research; The First Affiliated Hospital of The Fourth Military Medical University; Zhongshan hospital fudan university.

\section{Consent for publication}

All patients were informed that the reason for enrolling in the study was to collect natural history data for scientific analysis and publication (an obligation mandated by the Good Clinical Practice guidelines) and they signed consent forms with that understanding.

\section{Competing interests}

P.J.dV., E.B., T.C., V.C., P.C., G.B.d'A., J.C.K., J.C.F., M.F., C.F., C.H., S.J., R.N., F.O'C, J.Q., M.S., R.T., M.D., J.A.L., A.M., S.Y., M.P.B., B.Z. and A.C.J. received honoraria and support for the travels from Novartis. V.C. received personal fees for consulting, lecture fees and travel from Actelion, Bayer, Biogen Idec, Boehringer Ingelheim, Gilead, GSK, MSD, Novartis, Pfizer, Roche, Sanofi; grants from Actelion, Boehringer Ingelheim, GSK, Pfizer, Roche; personal fees for developing educational material from Boehringer Ingelheim and Roche. P.J.dV. has been on the study steering group of the EXIST-1, 2 and 3 studies sponsored by Novartis, and co-PI on two investigator-initiated studies partfunded by Novartis. RN received grant support, paid to her institution, from Eisai and lectures fees from Nutricia, Eisai, Advicenne and GW Pharma. Y.T. received personal fee from Novartis for lecture and for copyright of referential figures from the journals, and received grant from Japanese government for intractable epilepsy research. S.J. was partly financed by the EC Seventh Framework Programme (FP7/2007-2013; EPISTOP, grant agreement no. 602391), the Polish Ministerial funds for science (years 2013-2018) for the implementation of international cofinanced project and the grant EPIMARKER 
of the Polish National Center for Research and Development No STRATEGMED3/306306/4/2016. J.C.K., P.C., C.H., J.A.L., and J.Q. received research grant from Novartis. R.M., L.D'A. and S.S. are employees of Novartis. V.S. reported no competing interest. This study was funded by Novartis Pharma AG. All authors approved the final version of the manuscript prior to submission.

\section{Publisher's Note}

Springer Nature remains neutral with regard to jurisdictional claims in published maps and institutional affiliations.

\section{Author details}

'Division of Child and Adolescent Psychiatry, University of Cape Town, 46 Sawkins Road, Rondebosch, Cape Town 7700, South Africa. ${ }^{2}$ Research and Clinical Institute of Pediatrics, Pirogov Russian National Research Medical University, Moscow, Russian Federation. ${ }^{3}$ SPS Pediatrična Klinika, Ljubljana, Slovenia. ${ }^{4}$ TSA Tuberous Sclerosis Association, Nottingham, UK. ${ }^{5}$ Hôpital Louis Pradel, Claude Bernard University Lyon 1, Lyon, France. ${ }^{6}$ Tor Vergata University Hospital, Rome, Italy. ${ }^{7}$ Karolinska University Hospital, Stockholm, Sweden. ${ }^{8}$ Novartis Farma S.p.A, Origgio, Italy. ${ }^{9}$ Association Sclérose Tubéreuse de Bourneville, Gradignan, France. ${ }^{10}$ Centro Hospitalar Lisboa Ocidental, Lisbon, Portugal. ${ }^{11}$ Universitätsklinik für Kinder-und Jugendheilkunde, Vienna, Austria. ${ }^{12}$ Associazione Sclerosi Tuberosa ONLUS, Milan, Italy. ${ }^{13}$ European Tuberous Sclerosis Complex Association, In den Birken, Dattein, Germany. ${ }^{14}$ Vivantes-Klinikum Neukölln, Berlin, Germany. ${ }^{15}$ Department of Child Neurology, Warsaw Medical University, Warsaw, Poland. ${ }^{16}$ Sussex Kidney Unit, Royal Sussex County Hospital, Brighton, UK. ${ }^{17}$ The Tuberous Sclerosis Multidisciplinary Management Clinic, Sydney Children's Hospital, Randwick, NSW, Australia. ${ }^{18}$ Hospital Universitari Vall d'Hebron, Barcelona, Spain. ${ }^{19}$ Institute of Biomedicine, University of Leon, Leon, Spain. ${ }^{20}$ Department of Pediatric Neurology, Necker Enfants Malades Hospital, Paris Descartes University, Paris, France. ${ }^{21}$ Institute of Child Health, University College London, London, UK. ${ }^{22}$ Department of Pediatrics, Peking University People's Hospital (PKUPH), Beijing, China. ${ }^{23}$ Tallinn Children Hospital, Tallinn, Estonia. ${ }^{24}$ Klinikverbund Kempten-Oberallgäu gGmbH, Kempten, Germany. ${ }^{25}$ Novartis Healthcare Pvt. Ltd, Hyderabad, India. ${ }^{26}$ National Epilepsy Center, Shizuoka Institute of Epilepsy and Neurological Disorders, NHO, 886 Urushiyama, Aoi-ku, Shizuoka, Japan. ${ }^{27}$ Hôpital Nord, Saint Etienne, France. ${ }^{28}$ "St. Sophia" Children's Hospital, Athens, Greece. ${ }^{29}$ University Medical Center, Utrecht, The Netherlands. ${ }^{30}$ UZ Brussel Vrije Universiteit Brussel, Brussels, Belgium.

\section{Received: 16 January 2018 Accepted: 29 August 2018}

\section{Published online: 10 September 2018}

\section{References}

1. Crino PB, Nathanson $\mathrm{KL}$, Henske EP. The tuberous sclerosis complex. N Engl J Med. 2006:355:1345-56

2. Krueger DA, Northrup H. Tuberous sclerosis complex surveillance and management: recommendations of the 2012 international tuberous sclerosis complex consensus conference. Pediatr Neurol. 2013;49:255-65.

3. Curatolo P, Moavero R, de Vries PJ. Neurological and neuropsychiatric aspects of tuberous sclerosis complex. Lancet Neurol. 2015;14:733-45.

4. Curatolo P, Verdecchia M, Bombardieri R. Tuberous sclerosis complex: a review of neurological aspects. Eur J Paediatr Neurol. 2002;6:15-23.

5. de Vries PJ, Whittemore VH, Leclezio L, Byars AW, Dunn D, Ess KC, Hook D, King $\mathrm{BH}$, Sahin $\mathrm{M}$, Jansen A. Tuberous sclerosis associated neuropsychiatric disorders (TAND) and the TAND checklist. Pediatr Neurol. 2015;52:25-35.

6. Leclezio L, Jansen A, Whittemore VH, de Vries PJ. Pilot validation of the tuberous sclerosis-associated neuropsychiatric disorders (TAND) checklist. Pediatr Neurol. 2015;52:16-24.

7. Leclezio L, de Vries P. Towards an improved understanding of TSCassociated neuropsychiatric disorders (TAND). Adv Autism. 2016;2:76-83.

8. Prather P, de Vries PJ. Behavioral and cognitive aspects of tuberous sclerosis complex. J Child Neurol. 2004;19:666-74.

9. Muzykewicz DA, Newberry P, Danforth N, Halpern EF, Thiele EA. Psychiatric comorbid conditions in a clinic population of 241 patients with tuberous sclerosis complex. Epilepsy Behav. 2007;11:506-13.

10. Hunt A. Development, behaviour and seizures in 300 cases of tuberous sclerosis. J Intellect Disabil Res. 1993;37(Pt 1):41-51.
11. Gillberg IC, Gillberg C, Ahlsen G. Autistic behaviour and attention deficits in tuberous sclerosis: a population-based study. Dev Med Child Neurol. 1994; 36:50-6.

12. de Vries PJ, Hunt A, Bolton PF. The psychopathologies of children and adolescents with tuberous sclerosis complex (TSC): a postal survey of UK families. Eur Child Adolesc Psychiatry. 2007;16:16-24.

13. Leclezio L, Gardner-Lubbe S, de Vries PJ. Is it feasible to identify natural clusters of TSC-associated neuropsychiatric disorders (TAND)? Pediatr Neurol. 2018:81:38-44.

14. Hunt A. Tuberous sclerosis: a survey of 97 cases. III: family aspects. Dev Med Child Neurol. 1983;25:353-7.

15. Wilde L, Eden K, de Vries P, Moss J, Welham A, Oliver C. Self-injury and aggression in adults with tuberous sclerosis complex: frequency, associated person characteristics, and implications for assessment. Res Dev Disabil. 2017:64:119-30.

16. de Vries PJ, Howe CJ. The tuberous sclerosis complex proteins--a GRIPP on cognition and neurodevelopment. Trends Mol Med. 2007;13:319-26.

17. Ehninger D, de Vries PJ, Silva AJ. From mTOR to cognition: molecular and cellular mechanisms of cognitive impairments in tuberous sclerosis. J Intellect Disabil Res. 2009;53:838-51.

18. Waltereit R, Japs B, Schneider M, de Vries PJ, Bartsch D. Epilepsy and Tsc2 haploinsufficiency lead to autistic-like social deficit behaviors in rats. Behav Genet. 2011:41:364-72.

19. Schneider M, de Vries PJ, Schonig K, Rossner V, Waltereit R. mTOR inhibitor reverses autistic-like social deficit behaviours in adult rats with both TSC2 haploinsufficiency and developmental status epilepticus. Eur Arch Psychiatry Clin Neurosci. 2017:267(5):455-63.

20. Tsai P, Sahin M. Mechanisms of neurocognitive dysfunction and therapeutic considerations in tuberous sclerosis complex. Curr Opin Neurol. 2011;24:106-13.

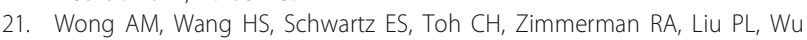
YM, Ng SH, Wang JJ. Cerebral diffusion tensor MR tractography in tuberous sclerosis complex: correlation with neurologic severity and tract-based spatial statistical analysis. AJNR Am J Neuroradiol. 2013;34: 1829-35.

22. Ridler K, Bullmore ET, De Vries PJ, Suckling J, Barker GJ, Meara SJ, Williams SC, Bolton PF. Widespread anatomical abnormalities of grey and white matter structure in tuberous sclerosis. Psychol Med. 2001;31: 1437-46.

23. Jansen FE, Braams $O$, Vincken KL, Algra A, Anbeek $P$, Jennekens-Schinkel A, Halley D, Zonnenberg BA, van den Ouweland A, van Huffelen AC, et al. Overlapping neurologic and cognitive phenotypes in patients with TSC1 or TSC2 mutations. Neurology. 2008;70:908-15.

24. Au KS, Williams AT, Roach ES, Batchelor L, Sparagana SP, Delgado MR, Wheless JW, Baumgartner JE, Roa BB, Wilson CM, et al. Genotype/ phenotype correlation in 325 individuals referred for a diagnosis of tuberous sclerosis complex in the United States. Genet Med. 2007;9:88-100.

25. van Eeghen AM, Black ME, Pulsifer MB, Kwiatkowski DJ, Thiele EA. Genotype and cognitive phenotype of patients with tuberous sclerosis complex. Eur J Hum Genet. 2012;20:510-5.

26. Wong HT, McCartney DL, Lewis JC, Sampson JR, Howe CJ, de Vries PJ. Intellectual ability in tuberous sclerosis complex correlates with predicted effects of mutations on TSC1 and TSC2 proteins. J Med Genet. 2015;52:815-22.

27. Kingswood JC, Bruzzi P, Curatolo P, de Vries PJ, Fladrowski C, Hertzberg C, Jansen AC, Jozwiak S, Nabbout R, Sauter M, et al. TOSCA - first international registry to address knowledge gaps in the natural history and management of tuberous sclerosis complex. Orphanet J Rare Dis. 2014;9:182.

28. Kingswood JC, d'Augeres GB, Belousova E, Ferreira JC, Carter T, Castellana R, Cottin V, Curatolo P, Dahlin M, de Vries PJ, et al. TuberOus SClerosis registry to increase disease awareness (TOSCA) - baseline data on 2093 patients. Orphanet J Rare Dis. 2017;12:2.

29. International Conference on Harmonisation of Technical Requirements for Registration of Pharmaceuticals for Human Use (ICH) adopts Consolidated Guideline on Good Clinical Practice in the Conduct of Clinical Trials on Medicinal Products for Human Use. Int Dig Health Legis 1997, 48:231-234.

30. World Medical Association Declaration of Helsinki. Ethical principles for medical research involving human subjects. JAMA. 2013;310(2194):2191.

31. American Psychiatric Association. Diagnostic and statistical manual of mental disorders. 5th ed. Arlington: American Psychiatric Publishing; 2013. 
32. World Health Organization. ICD-10: international statistical classification of diseases and related health problems. 10th revision. 2nd ed: Geneva World Health Organization; 2004.

33. Kopp CM, Muzykewicz DA, Staley BA, Thiele EA, Pulsifer MB. Behavior problems in children with tuberous sclerosis complex and parental stress. Epilepsy Behav. 2008;13:505-10.

34. Northrup H, Krueger DA. Tuberous sclerosis complex diagnostic criteria update: recommendations of the 2012 International tuberous sclerosis complex consensus conference. Pediatr Neurol. 2013;49:243-54.

35. de Vries P, Humphrey A, McCartney D, Prather P, Bolton P, Hunt A Consensus clinical guidelines for the assessment of cognitive and behavioural problems in tuberous sclerosis. Eur Child Adolesc Psychiatry. 2005:14:183-90

36. Vignoli A, La Briola F, Peron A, Turner K, Vannicola C, Saccani M, Magnaghi E, Scornavacca GF, Canevini MP. Autism spectrum disorder in tuberous sclerosis complex: searching for risk markers. Orphanet J Rare Dis. 2015;10:154.

37. Wong V. Study of the relationship between tuberous sclerosis complex and autistic disorder. J Child Neurol. 2006;21:199-204.

38. Dabora SL, Jozwiak S, Franz DN, Roberts PS, Nieto A, Chung J, Choy YS, Reeve MP, Thiele E, Egelhoff JC, et al. Mutational analysis in a cohort of 224 tuberous sclerosis patients indicates increased severity of TSC2, compared with TSC1, disease in multiple organs. Am J Hum Genet. 2001;68:64-80.

39. Joinson C, O'Callaghan FJ, Osborne JP, Martyn C, Harris T, Bolton PF. Learning disability and epilepsy in an epidemiological sample of individuals with tuberous sclerosis complex. Psychol Med. 2003;33:335-44.

40. Winterkorn EB, Pulsifer MB, Thiele EA. Cognitive prognosis of patients with tuberous sclerosis complex. Neurology. 2007;68:62-4.

Ready to submit your research? Choose BMC and benefit from:

- fast, convenient online submission

- thorough peer review by experienced researchers in your field

- rapid publication on acceptance

- support for research data, including large and complex data types

- gold Open Access which fosters wider collaboration and increased citations

- maximum visibility for your research: over $100 \mathrm{M}$ website views per year

At $\mathrm{BMC}$, research is always in progress.

Learn more biomedcentral.com/submissions 